\title{
As máquinas inteligentes e o impacto sobre os empregos
}

\section{Smart machines and the impact on jobs}

\section{El maquinário inteligente y sus impactos em los empleos}

\author{
Sales, Ana Patrícia Dias ${ }^{1}$ (Fortaleza, Ceará e Brasil) \\ ORCID ID: https://orcid.org/0000-0002-6070-884X \\ Sales, Francisco José Lima² (Fortaleza, Ceará e Brasil) \\ ORCID ID: https://orcid.org/0000-0002-2642-0383
}

\begin{abstract}
Resumo
O estudo é parte de uma pesquisa maior sobre a dinâmica do mercado de trabalho na cidade do Natal/RN, no entanto, a análise aqui desenvolvida circunscreve-se ao setor supermercadista. O objetivo é analisar os impactos não somente da adoção das máquinas inteligentes, os Self-Checkouts, sobre o trabalho dos operadores de caixa de supermercados, bem como das relações de trabalho, e demarcar a compreensão deles sobre a Quarta Revolução Industrial. A pesquisa tem como período referencial o ano de 2018 e se embasa em dados primários e secundários. Constata-se que a falta de conhecimento dos trabalhadores de supermercados no tocante à Revolução 4.0 os faz acreditarem que as novas tecnologias não são poupadoras do trabalho vivo e, por conseguinte, não afetarão seus empregos e muito menos provocarão desemprego.
\end{abstract}

Palavras-chave: Desemprego. Revolução 4.0. Self-Checkout. Supermercados.

\begin{abstract}
The study is part of broader research on the dynamics of the labor market in Natal/RN. However, the analysis developed here is limited to the retail food sector, specifically to supermarkets. The objective is to analyze the impacts not only on the adoption of smart machines (self-checkout terminals) on the work of supermarket cashier operators as well as of labor relations, and also to demarcate their understanding of the Fourth Industrial Revolution. The research has, as a reference period, the year 2018 , and it is based on primary and secondary data. These workers' lack of knowledge of the real employment impacts of Revolution 4.0 shows they believe new technologies are not a sparer of living labor, and therefore, will not affect their jobs, let alone cause unemployment.
\end{abstract}

Keywords: Unemployment. Revolution 4.0. Self-Checkout. Supermarkets.

\section{Resumen}

Este estudio es parte de una investigación más amplia sobre la dinámica del mercado de trabajo en la ciudad de Natal en Rio Grande do Norte - Brasil. Se trata de un analisis del sector de supermercados. El objetivo es analisar los impactos de la adopción de maquinario inteligente, los self-chekouts, en el trabajo de los cajeros de supermercados y sus relaciones de trabajo, y remarcar su comprensión en relación a la Cuarta Revolución Industrial. Esta investigación se ubica en el año 2018 y se basa en datos primarios y secundarios. Se constató que la falta de conocimiento de los trabajadores de

\footnotetext{
${ }^{1}$ Professora adjunta do curso de Ciências Sociais da Universidade Federal do Rio Grande do Norte e do Programa de Pós-Graduação em Estudos Urbanos e Regionais - PPEUR. anapatricia_dias@yahoo.com.br

2 Professor da Universidade Federal do Ceará (UFC), lotado no Departamento de Estudos Especializados da Faculdade de Educação (FACED) membro do Programa de Pós-Graduação em Educação Brasileira. chicodede@gmail.com
} 
supermercados en lo que dice respeto a la Revolución 4.0 hace que crean que las nuevas tecnologías no ahorran trabajo vivo y, por ello, no afectan sus empleos y tampoco provocarán el paro.

Palavras-Clave: Desempleo. Revolución 4.0. Autocomprobación. Supermercados.

\section{Introdução}

O capitalismo contemporâneo, marcado por sua fase imperialista, vem impulsionando, desde os anos de 1970, relevantes mudanças na forma de produzir mercadorias, de desenvolver atividades e de vender serviços. Essas alterações refletiram no mundo do trabalho, assim como nos vendedores da força de trabalho, promovendo não somente novas maneiras de pensar a produção e os serviços, bem como novas formas de os trabalhadores se relacionarem com a atividade laboral.

Mais recentemente, a humanidade testemunha uma nova transformação com impactos no mundo do trabalho, instigada pela denominada Indústria 4.0 ou, numa expressão mais propícia ao contexto, pela Quarta Revolução Industrial, caracterizada como uma revolução radical e de alcance inimaginável.

No âmbito das empresas, esse contexto representa o incremento de novas tecnologias conectadas à internet e equipadas com sensores e softwares capazes de coletar e de interpretar inúmeros dados e informações, cujo objetivo é produzir em maior escala, em menor tempo e com maior eficiência, visando reduzir custos e aumentar a taxa de lucro.

No Brasil, a Indústria 4.0 ainda é muito incipiente quando comparada aos países centrais, embora se admita que empresas de médio e de grande porte avancem rumo a essa fase. Para os defensores da Indústria 4.0, para que o País siga nessa direção, os empresários e os governos precisam romper com a lógica de uma cultura empresarial pautada em um padrão de controle físico da produção e passem a adotar sistemas digitais, nos quais a automatização dos processos, assim como a robótica, ganhem proeminência.

É nesse contexto de mudanças expressivas no padrão de produção e dos serviços rumo à Indústria 4.0 que se inscreve este estudo. A análise demarca o setor de varejo alimentício, isto é, a rede de supermercados, para desenvolver a pesquisa, uma vez que se identificou que esse ramo da economia vem adotando tecnologias 
próprias desse momento histórico, a exemplo dos Self-checkouts. Trata-se de um modelo de caixa inteligente de autoatendimento, que permite ao cliente realizar, sozinho, todas as etapas de sua compra: pesar produtos, registrar códigos de barras, embalar as mercadorias e realizar o pagamento.

Assim, o objetivo do artigo é analisar os impactos da adoção das máquinas inteligentes sobre o trabalho dos operadores de caixa e sobre as relações de trabalho no interior de quatro supermercados na cidade do Natal/RN, que vêm adotando, desde 2018, essas tecnologias. Parte-se do pressuposto de que a falta de conhecimento dos trabalhadores de supermercados no tocante à revolução que está em curso os faz acreditarem que as novas tecnologias não são poupadoras de trabalho vivo e, por conseguinte, não afetarão o emprego deles e tampouco provocarão desemprego.

No caso, demarcaremos a compreensão dos trabalhadores de supermercado, especificamente os operadores de caixa, sobre a Quarta Revolução Industrial e o impacto sobre o trabalho e as relações de trabalho. Na oportunidade, a reflexão também delimita dois dos elementos da relação de emprego, a saber, o tipo de vínculo empregatício e a remuneração, no intuito de qualificar e de caracterizar as ocupações.

$\mathrm{Na}$ sequência, discorre-se, sucintamente, sobre as distintas revoluções, seguida da demarcação das máquinas inteligentes no interior dos supermercados, e sobre a compreensão dos operadores de caixas a respeito delas.

\section{Da revolução industrial à revolução 4.0: breve histórico}

Antes de nos determos sobre as características da Indústria 4.0, é importante historicizar, embora de forma breve, o surgimento da Grande Indústria, ocorrido na passagem do século XVIII para o século XIX, que provocou uma enorme aceleração da produção de bens, tornando o crescimento econômico independente da agricultura.

É bem verdade que o advento da industrialização se associa à história do desenvolvimento do capitalismo, uma vez que, com o surgimento da máquinaferramenta e do vapor, o mundo entrou definitivamente na era capitalista. Essa Primeira Revolução Industrial desponta como uma das mais profundas mudanças já 
vistas na história da espécie humana, o que possibilitou ao modo de produção capitalista se propagar e se consolidar por todo o Globo.

As invenções e inovações decorrentes desse momento histórico emergiram com o renascimento do comércio na Europa, bem como com o surgimento do tear mecânico na indústria algodoeira, o qual intensificou a produção de tecidos, particularmente na Inglaterra, berço da Primeira Revolução Industrial.

Assim, a indústria têxtil desponta como a pioneira na mecanização da produção. Depois dela, outros setores sucumbiram às inovações e assim passaram a utilizar as máquinas como meios de trabalho. A siderurgia, ao revolucionar o seu processo de trabalho, produziu efeitos ainda maiores, uma vez que impactou todo o desenvolvimento industrial posterior. Como desdobramento,

[...] uma série de aperfeiçoamentos em fornos e sistemas de fundição permitiu obter ferro de alta qualidade, capaz de substituir vantajosamente outros materiais para melhorar muitas técnicas existentes e construir novas máquinas. Somente o ferro permitiu o desenvolvimento das estradas de ferro, que vieram a somar-se às importantes transformações no sistema de transporte, que já haviam começado a produzir-se, tais como: técnicas modernas de pavimentação de estradas e abertura de redes de canais. A diminuição do tempo de deslocamento e o intercâmbio, que assim se tornou possível, iniciaram a ruptura das relações de dependência entre núcleos urbanos e rurais, próprias da sociedade agrícola anterior (DIAS, 2004, p. 15).

Nesse sentido, o gradativo avanço e sofisticação das máquinas e o consequente aumento da produção industrial resultaram na geração de um montante expressivo de capital que, por sua vez, foi reaplicado no desenvolvimento de novas máquinas. Logo, tanto a intensificação da mecanização quanto o posterior aprimoramento do maquinário resultarão no revolucionamento contínuo das forças produtivas da época que, por sua vez, promoverão o barateamento das mercadorias e a venda em grandes quantidades.

Por outro lado, as transformações que tiveram início a partir do primeiro quartel do século XVIII promoverão a superexploração do trabalho da recém-formada classe operária, já que, diferente da manufatura, em que o trabalhador ainda exercia algum controle sobre o processo de trabalho, nas fábricas, a máquina passa a impor o ritmo da produção, transformando o trabalhador em simples apêndice desse instrumental. Isto é, o surgimento da maquinaria irá promover a subordinação técnica 
do trabalhador ao ritmo uniforme do instrumental, que será submetido também a longas e extenuantes jornadas de trabalho.

Logo, como aponta Dias (2004), o que se convencionou chamar originalmente de Revolução Industrial apresentou uma série de traços que a diferenciou da manufatura. Entre eles podem ser citados: a substituição progressiva do trabalho humano por máquinas; a divisão técnica do trabalho e a necessidade de sua coordenação; mudanças culturais no trabalho; a produção maciça de bens e o surgimento de novas classes sociais: capitalistas e operários. Já os principais avanços tecnológicos conhecidos nessa fase foram: o uso do carvão como fonte de energia para a máquina a vapor; o desenvolvimento da máquina a vapor e a criação da locomotiva; a invenção do telégrafo; o aparecimento de indústrias têxteis, como a do algodão, e a ampliação da indústria siderúrgica.

Nesse sentido, o avanço da Revolução Industrial para outros países europeus (como França, Bélgica, Holanda e Alemanha) - que vai da segunda metade do século XIX até aproximadamente as duas primeiras décadas do século $X X-$, bem como para os Estados Unidos, inaugurará uma segunda onda de revoluções industriais, que apresentará características completamente distintas daquelas do primeiro ciclo. Esse lapso temporal assume

[...] uma incontida dinâmica, impulsionada por inovações técnicas, como a descoberta da eletricidade, a transformação de ferro em aço, o surgimento e o avanço dos meios de transporte e, mais tarde, dos meios de comunicação, o desenvolvimento da indústria química e de outros setores (SILVA e GASPARIN, 2013, p. 6).

A nascente Segunda Revolução Industrial apresentará ainda uma série de traços ou tendências gerais distintas do momento anterior. Entre elas podem ser apontados: a busca por uma maior lucratividade em relação aos investimentos realizados; a especialização do trabalho levada às últimas consequências e a produção em série, que reduziu substancialmente o custo unitário das mercadorias.

As principais inovações dessa fase da revolução estão associadas à aplicação de novas fontes de energia (carvão mineral, gás natural e petróleo) e de novas técnicas de produção, com destaque para a indústria química. O uso da eletricidade se expandiu para a iluminação urbana, residencial e industrial; ocorreu a 
extensão do uso da energia elétrica, que permitiu a criação dos motores elétricos, e os combustíveis fósseis, como os derivados do petróleo, foram utilizados largamente como fontes importantes de geração de energia na indústria. A difusão desse combustível fóssil ocorreu graças à invenção do motor à explosão.

Para Silva e Gasparin (2013), outra característica desse novo ciclo foi o surgimento da linha de montagem fordista, que, ao permitir um ganho de produtividade até então inimaginável, reverteu esses ganhos na diminuição dos custos de produção, possibilitando, assim, um aumento espetacular dos lucros dos capitalistas.

Logo, ao provocar mudanças que alteraram significativamente o modo de produção da vida material dos indivíduos nessa quadra histórica, a Segunda Revolução Industrial irá fixar as bases do progresso tecnológico e científico, visando à invenção e ao aperfeiçoamento constantes de novos produtos e técnicas que melhoram o desempenho industrial.

A Terceira Revolução Industrial, por sua vez, representa o começo de um novo patamar econômico e social na sociedade capitalista. Desse modo, o advento de novas tecnologias da informação, surgidas a partir da segunda metade do século $X X$, e a sua adoção de forma industrial dão origem ao que se convencionou chamar de "a era da informação".

Esse novo momento histórico, também conhecido como Revolução Técnico-Científica Informacional, é marcado especialmente pelo aperfeiçoamento de técnicas e avanços tecnológicos tanto no campo das ciências (puras e aplicadas) como no processo produtivo. Essa fase se caracterizará ainda pelo surgimento e pela rápida expansão da informática (computadores mainframe, computadores pessoais e a internet) e da automação, que resultaram em avanços, outrora nunca antes vistos, em áreas como a robótica, as telecomunicações, os transportes e a genética.

A nova configuração ocasionada por essa leva de inovações tecnológicas (de processos e produtos), diferente das revoluções pretéritas, quando se observou uma crescente substituição do trabalho manual pela máquina e a transformação dos detentores da força de trabalho em meros apêndices de um maquinário cada vez mais complexo, ganhou novas e maiores proporções. Com o uso extensivo de 
computadores, a força de trabalho será largamente substituída por softwares que, em muitos casos, passam a gerir completamente o processo de trabalho.

Embora a Terceira Revolução Industrial ganhe destaque a partir dos avanços tecnológicos e científicos observados no setor industrial, será com a expansão do setor terciário - em que a maior parte dos empregos gerados se concentra no setor de comércio e de serviços -, que se observará um aumento da aplicação dessas inovações, como a informatização.

Como visto, as primeiras revoluções industriais permitem o surgimento de inovações que alteraram significativamente o modo de produção da vida material da humanidade. A Primeira Revolução Industrial ocorreu com a invenção da máquina a vapor, que permitiu a intensificação da produção de mercadorias em menos tempo. Com a descoberta da eletricidade, ocorre a Segunda Revolução, que, posteriormente, possibilita a criação da linha de montagem e da produção em massa, do motor a combustão etc. A Revolução Técnico-Científica Informacional, a terceira das revoluções, impulsionada pela aplicação das primeiras tecnologias da informação, desenvolve ainda mais a automação da produção, com o uso massivo de computadores.

Já a Quarta Revolução Industrial, ou a Indústria 4.0, tendencialmente tem um impacto muito mais profundo e exponencial do que as anteriores, na medida em que promete tornar os sistemas convencionais de produção gradualmente obsoletos. Tal fenômeno se caracteriza por um conjunto de tecnologias que viabiliza a fusão do mundo físico, digital e biológico, que, ao possibilitar a geração de uma grande quantidade de dados, permite, por sua vez, que as próprias máquinas, uma vez conectadas à internet, possam interagir entre si e, a partir daí, criar novos padrões de execução de funções, tomando decisões e até se autocorrigindo de forma praticamente autônoma,

Para Schwab (2016), o surgimento da Quarta Revolução Industrial, ou a Indústria 4.0, implicaria nada mais nada menos do que a transformação de toda a humanidade. Segundo o autor citado, estaríamos vivenciando uma revolução tecnológica que transformará fundamentalmente a forma como vivemos, trabalhamos 
e nos relacionamos. Em sua escala, alcance e complexidade, a transformação será diferente de qualquer coisa que o ser humano tenha experimentado antes.

Nesse sentido, essa nova fase seria impelida por um complexo de tecnologias disruptivas ${ }^{3}$ como a robótica, a inteligência artificial, a realidade aumentada, a big data (análise de volumes massivos de dados), a nanotecnologia, a impressão 3D, a biologia sintética, a computação em nuvem e a chamada internet das coisas, em que cada vez mais dispositivos, equipamentos e objetos seriam conectados uns aos outros por meio da internet.

No entanto, a Indústria 4.0 não pode ser definida apenas por cada uma dessas inovações isoladamente, mas pela confluência e coesão entre as novas tecnologias. O que, de fato, estaria ocorrendo seria uma junção entre o mundo digital - artificial -, o mundo físico - as "coisas" - e o mundo biológico - os seres vivos, inclusive os homens.

Destarte, se, por um lado, os avanços da Quarta Revolução Industrial apresentam capacidade suficiente para aumentar a flexibilidade, a velocidade, a produtividade e a qualidade de produtos, serviços e processos, ou seja, a aplicação de técnicas que proporcionam o aumento da produtividade e eficiência produtiva, por outro lado, suas consequências vão muito além, de modo a afetar a economia como um todo, aí incluídas as empresas e os empregos.

No plano do emprego, além de evidenciar que profissões que envolvem o trabalho mecânico repetitivo e o trabalho manual de precisão já estejam eliminadas do processo de trabalho pela aplicação da automação, Schwab (2016) observa que outras categorias seguem o mesmo caminho. Segundo o autor,

Até o momento, a evidência é a seguinte: a quarta revolução industrial parece estar criando menos postos de trabalho nas novas indústrias do que as revoluções anteriores. De acordo com uma estimativa do Oxford Martin Programme on Technology, apenas $0,5 \%$ da força de trabalho dos EUA está empregada em indústrias que não existiam na virada do século, uma porcentagem muito menos do que os aproximadamente $8 \%$ de novos postos de trabalho criados em novas indústrias durante a década de 1980 e os 4,5\%

\footnotetext{
${ }^{3}$ Segundo Schwab (2016), disruptura significa que a velocidade das inovações estaria mais rápida do que nunca. Exemplos de disruptores, nomes desconhecidos há poucos anos, seriam a Airbnb, a Uber, a Alibaba etc. O iphone, lançado em 2007, alcançou a marca de 2 bilhões de smartphones em menos de uma década. Os carros autônomos, lançados em 2010 pela Google, já podem ser considerados uma realidade em alguns lugares do mundo.
} 
de novos postos de trabalho criados durante a década de 1990. O fato é corroborado por um recente censo econômico dos EUA, que esclarece que as inovações em tecnologias da informação e em outras tecnologias descontinuadoras tendem a elevar a produtividade por meio da substituição dos trabalhadores existentes; mas não por intermédio da criação de novos produtos que necessitam de mais trabalho para serem produzidos (SCHWAB, 2016, p.43).

No tocante aos impactos sobre a quantidade de postos de trabalho, Tessarini Junior e Saltorato (2018) afirmam que, em 2015, o Fórum Econômico Mundial realizou um estudo em que mostra a potencialidade da Indústria 4.0 em gerar o desemprego tecnológico, causado pelo uso intensivo de novas tecnologias que levam a obsolescência do trabalho humano. Segundo esses autores, o FEM

[...] realizou a maior pesquisa global sobre o assunto, cujo objetivo principal era compreender como as mudanças tecnológicas e sociodemográficas em andamento afetariam o trabalho até 2020. [...] Os resultados da pesquisa foram divulgados em 2016 no Report "The Futere of Jobs: Employment, Skills and Workforce Strategy for the Fourth Industrial Revolution" e apontam que a quarta revolução industrial provocará a perda de 7,1 milhões de empregos, enquanto 2 milhões serão criados, resultando em um impacto negativo de 5,1 milhões de postos de trabalho até 2020 , dos quais somente no setor de manufatura e produção mais de 1,6 milhões de empregos diretos serão substituídos por robôs e outras tecnologias avançadas (TESSARINI JUNIOR E SALTORATO, 2018, p. 758)

No entanto, a escala e a amplitude dos impactos ocasionados pela Indústria 4.0 poderão incidir não somente no plano do emprego, com a redução de postos de trabalho e a substituição do trabalho pelo uso de novas tecnologias, mas também se desdobrarão sobre aspectos como a formação da força de trabalho, uma vez que os trabalhadores necessitarão, para se tornarem empregáveis, de outros conhecimentos e habilidades (competências) que os tornem capazes de lidar com as novas tecnologias, o que faz dessa exigência por qualificação, aliada também ao envelhecimento progressivo da população, alguns dos maiores desafios sociais a serem enfrentados (SCHWAB, 2016).

No Brasil, embora a Confederação Nacional da Indústria (CNI/2017) reconheça que a rápida disseminação da atual revolução tecnológica no mundo indica que a sua aplicação no País poderá também ocorrer mais rapidamente se comparada com a das revoluções pretéritas, a CNI também observa que, para as empresas nacionais conseguirem competir internacionalmente com as maiores economias do 
mundo, elas deverão promover um salto tecnológico capaz de se adaptar à Indústria 4.0 já presente nesses países.

Vejamos a realidade do setor de varejo alimentício, isto é, a rede de supermercados no tocante à adoção das máquinas inteligentes.

\section{Os supermercados e os novos operadores de caixa: as máquinas inteligentes}

A Indústria 4.0 tem sido fonte de debates em todo o mundo. Trata-se de uma revolução radical decorrente da confluência de distintas áreas do conhecimento, a exemplo da inteligência artificial (IA), da robótica, da internet das coisas, da biotecnologia, da nanotecnologia, entre outras. Tais tecnologias, oriundas dessa tendência, embora não percebidas em demasia pelas pessoas e tampouco desenvolvida de igual modo pelas nações, já se anunciam e demarcam alterações no mundo do trabalho.

Atente-se que as plataformas digitais, os carros autônomos, a impressão em 3D e as máquinas inteligentes são algumas das invenções postas na contemporaneidade, decorrentes dessa nova processualidade, que modificam não somente as relações de trabalho, como também impactam no mercado de trabalho.

No Brasil, a discussão sobre a Indústria 4.0 é considerada incipiente, pois desponta na primeira década dos anos 2000, ainda que se perceba que empresas de médio e de grande porte, a exemplo da Volkswagen, da Jeep, da AmBev, dos bancos e dos supermercados avancem rumo a essa fase.

Na verdade, há certa expectativa frente à conjuntura econômica no País de que o empresariado brasileiro passe a adotar, em maior escala, as novas tecnologias digitais na rotina do trabalho, pois se vende a ideia de que a competitividade da indústria e dos serviços dependerá da capacidade de o produtor nacional incorporar as novas tecnologias da considerada Revolução 4.0, permitindo que as empresas possam competir em igualdade de condições nos mercados interno e externo.

No caso, destaca-se o setor de varejo alimentício, isto é, a rede de supermercados para evidenciar como esse ramo da economia vem incorporando as tecnologias desse momento histórico, a exemplo dos Self-checkouts, modelo de 
máquinas inteligentes em que os consumidores processam suas compras, embalam e realizam pagamentos, sem o auxílio de operadores de caixa.

De todo modo, faz-se mister salientar que, embora as máquinas de autoatendimento não sejam novidades no interior dos supermercados de algumas realidades, como a europeia e a americana, no Brasil - e em particular na cidade do Natal/ RN -, local de desenvolvimento do estudo, o uso dessa tecnologia é algo inusitado no contexto dos supermercados, vindo gradativamente se expandindo e metamorfoseando o ambiente e as relações de trabalho.

$\mathrm{Na}$ cidade do Natal/RN, duas redes de supermercados vêm adotando essa tecnologia desde o ano de 2018. O investimento nas máquinas inteligentes permite que os consumidores realizem procedimentos e operações que outrora eram realizados pelos embaladores e operadores de caixa, promovendo, além disso, novas formas de sociabilidade entre o consumidor e o supermercado. Como aponta Dias (2014), a pessoalidade tão somente existente entre o cliente, o operador de caixa e o embalador passa a ser substituída pela relação consumidor/máquina.

Há de se convir que o incremento desse processo de automação dos operadores de caixas no interior dos supermercados, por meio das máquinas inteligentes, implica drásticas mudanças no cotidiano social do ambiente de trabalho. Essas famosas máquinas, que, paradoxalmente, provocam resistência entre alguns consumidores e deslumbre em outros, revolucionam o tradicional atendimento nos supermercados e tendem a transformar essas lojas do ramo de varejo alimentício em ambientes automatizados.

Assim, os supermercados vão adotando espaços específicos para os serviços de autoatendimento e de comercialização dos serviços, deixando à disposição dos clientes funcionários para orientá-los e dirimir eventuais dúvidas quanto ao uso das máquinas. Nesses caixas, há limites de itens por clientes, não podendo ultrapassar 20 , além de que o pagamento deve ser realizado tão somente por meio de cartões de crédito ou débito.

Segundo o gerente de um dos supermercados, em entrevista cedida ao Agora Natal (2018), a empresa não pretende acabar com os terminais tradicionais tampouco com os operadores de caixas e embaladores, pois os caixas tradicionais 
são utilizados por outro perfil de clientes, que preferem o atendimento tradicional, pois há muitos clientes que não têm intimidade com a tecnologia e se sentem mais confortáveis passando as suas compras com pessoas. Para o gerente, as máquinas vão proporcionar aos clientes agilidade e eficiência nunca vista em outros métodos, além de evitar filas e tempo de espera. Esse discurso também foi apropriado pelos operadores de caixa, ao afirmarem que o objetivo das máquinas inteligentes

[...] é evitar que o cliente passe muito tempo na fila, evita que ele fique esperando, pois permite que o cliente passe poucas compras. Essa é uma mudança muito boa, é uma forma de deixar mais rápido e prático o serviço prestado pelos caixas (OPERADOR DE CAIXA, 2018).

Os benefícios do processo de automatização dos operadores de caixas, indubitavelmente, trazem um conjunto de vantagens não somente para os clientes, como dito pelo gerente, mas, sobretudo, para a empresa que projeta reduzir o seu investimento em capital fixo e investir em novas tecnologias, tendendo a substituir cada vez mais o trabalho vivo pelo trabalho morto. As máquinas inteligentes, além de transferirem todas as etapas do trabalho para o consumidor (como passar a compra, pesar, embalar e pagar), são poupadoras de força de trabalho porque, a médio e/ou longo prazo, tendem a reduzir o número de funcionários.

Essa tendência de uma possível redução de postos de trabalhos decorrente do processo de automatização parece não passar pelo imaginário dos operadores de caixa, que, de modo geral, além de não perceberem a implantação das máquinas inteligentes no ambiente em que laboram, em sua maioria, nunca ouviram falar da Revolução 4.0. Aqui, remete-se à compreensão de 18 trabalhadores que atuam nas redes de supermercados, os quais estão na faixa etária predominante entre 20 a 30 anos de idade, prevalentes do sexo feminino, a maioria com grau de instrução de ensino médio completo, com distintos contratos de trabalhos e remuneração variando entre meio a um salário comercial.

Essa compreensão dos operadores de caixas, descolada da conjuntura em que se vive e das mudanças processadas no próprio ambiente de trabalho, conflui para que eles não vislumbrem correlação de ameaças entre os caixas de 
autoatendimento e a função que ocupam no interior dos supermercados. Isto porque compreendem que

[...] as máquinas inteligentes são interessantes, rápidas e agilizam as compras. Dizem que elas vão desempregar os operadores de caixas, mas, se isso acontecer, será no futuro porque, até agora, não desempregou ninguém. Tem gente que só passa as compras nelas, outras só querem os caixas com funcionários. Elas são boas e não vão tirar o nosso emprego, mas muita gente foi demitida da empresa, mas a culpa não foi das máquinas (OPERADOR DE CAIXA, 2018).

Se, por um lado, parte dos operadores de caixas entende ser interessante as máquinas inteligentes, há outro percentual que diz não ser algo tão fácil de lidar no cotidiano das compras, razão pela qual não vai desempregar os funcionários. Como afirmou um entrevistado,

[...] as máquinas inteligentes são complicadas, dão muito problema, param o tempo todo. Os clientes não têm paciência e, no fim, voltam para os caixas normais. Essas máquinas não vão vingar, é por isso que não vai desempregar os operadores de caixas. Além disso, o pagamento nelas só é realizado com cartão e tem gente que quer pagar somente com dinheiro (OPERADOR DE CAIXA, 2018).

A partir da compreensão dos trabalhadores de supermercados no tocante ao autoatendimento, depreende-se que a falta de conhecimento deles no tocante à revolução que está em curso os faz acreditarem que as novas tecnologias não são poupadoras do trabalho vivo e, por conseguinte, não afetarão o emprego deles e tampouco provocarão desemprego. Aliás, o seu incremento, como afirma um entrevistado, "possibilitará ao empregado experienciar outras oportunidades de trabalho e ser remanejado para ocupar outras funções dentro da empresa quando passar a fase de teste".

Talvez essa compreensão justifique o porquê de eles não sentirem os seus empregos ameaçados por essa tecnologia, ainda que apontem a demissão de alguns operadores de caixa após a implantação das máquinas e o remanejamento de outros empregados para ocupar outras funções, inclusive para auxiliar os consumidores a realizar as operações nas máquinas.

Certamente, após o domínio dessa tecnologia pela clientela, esses trabalhadores tendem a ter os seus dias contados na empresa, pois, como alerta 
Schwab (2016), o risco da automação para os empregos é uma realidade tanto nos países desenvolvidos quanto nas economias emergentes. Essa situação rebaterá diretamente em dois distintos profissionais que, no mínimo, deixarão de ser contratados ou poderão ser desligados da empresa, a saber, os operadores de caixas e os embaladores. Ademais, em um futuro não muito distante, poderão deixar de existir profissionalmente, embora essa não seja a compreensão da maioria dos trabalhadores entrevistados, uma vez que desconhecem que o mundo vive o contexto da denominada Quarta Revolução Industrial.

O desdobramento dessa realidade será uma sociedade marcada por uma desigualdade ainda mais exacerbada frente às consequências que a Revolução 4.0 fomentará nos ambientes de trabalho, no mercado de trabalho de modo geral e na vida do trabalhador, em particular.

Estudiosos como Rifkin (2000) e Schwab (2016), entre outros, apontam como a computação e a robótica, associadas a outras tecnologias, eliminam funções e profissões, o que é extremamente preocupante para a compreensão quanto ao rumo para onde a sociedade do trabalho assalariado está caminhando, uma vez que se distancia cada vez mais do emprego regular, normativo e com renda satisfatória, referenciado no padrão de trabalho fordista.

\section{Considerações finais}

Diante do exposto, pode-se concluir que as pretéritas revoluções industriais foram fenômenos marcantes na história da humanidade ao transformarem as relações sociais, as relações de trabalho e o sistema produtivo. As consequências foram muitas e estão relacionadas à cada fase vivida no processo evolutivo das tecnologias que proporcionou a industrialização dos países capitalistas. Desde a máquina a vapor, passando pela linha de montagem e pela tecnologia da informação, a competição tecnológica tornou-se o centro do desenvolvimento econômico capitalista.

Entretanto, o desenvolvimento tecnológico ao mesmo tempo que promoveu a mudança do estilo de vida da humanidade, implicou também inúmeras consequências para a sociedade, que vão desde o êxodo rural, passando pelo crescimento desenfreado das cidades, bem como pela extinção de incontáveis postos 
de trabalho por meio da substituição da força de trabalho pelas inovações tecnológicas. Esse último aspecto, o fenômeno do desemprego tecnológico, se tornou um espectro que passou a rondar a vida cotidiana dos trabalhadores desde os primórdios da Revolução Industrial no século XVIII.

No que se refere à Indústria 4.0, é consenso entre os especialistas que os impactos positivos sobre a produtividade, como a redução de custos, o controle sobre o processo produtivo, a customização da produção, dentre outros, apontam para uma transformação profunda no "chão de fábrica". No entanto, a grande incógnita recai sobre as consequências que a Quarta Revolução Industrial trará sobre o mercado de trabalho, uma vez que as novas tecnologias, ao mudarem drasticamente a natureza do trabalho em todos os setores e ocupações, trazem a incerteza sobre a quantidade de postos de trabalho que serão substituídos pela automação.

Segundo Schwab (2016), essa incerteza se justificaria em razão da evidência de que a Quarta Revolução Industrial estaria criando menos postos de trabalho do que as revoluções anteriores. Essa evidência se mostraria verdadeira em virtude da automatização dos postos de trabalho de algumas categorias de trabalho, principalmente naquelas que envolvem o trabalho de precisão, mecânico e repetitivo; além do fato de que outras categorias estariam, tendencialmente, seguindo o mesmo caminho, caso a capacidade de processamento continue a crescer exponencialmente, como advogados, analistas financeiros, médicos, jornalistas, contadores, bibliotecários etc.

Nessa perspectiva, pode-se afirmar que, no contexto dos supermercados, profissões como os de operadores de caixas e de embaladores tendem a ser reduzidas e/ou até suprimidas com a adoção das máquinas inteligentes. Essas máquinas são capazes de executar tarefas de forma mais barata do que os trabalhadores e os processos são mais eficientes. Aqui, refere-se aos trabalhadores sem maiores formações, habilidades e competências, ou seja, trabalhadores de atividades repetitivas, embora essa realidade atinja as mais distintas categorias.

Assim, as sociedades se colocam diante de um grande desafio, que é compreender o momento histórico e impor limites, se possível for, ao avanço tecnológico, que surpreende pelo tom da velocidade. O desdobramento dessa 
revolução já se percebe, sobretudo, no mundo do trabalho e no estilo de vida que se impõe aos homens, marcando uma sociedade cada vez mais desigual e com elevado índice de desemprego. Não sem razão, já se discute uma renda mínima universal para garantir a sobrevivência da massa de excluídos.

\section{Referências}

DIAS, Ana Patrícia. A terceirização da força de trabalho: precarização, desigualdade e conflitos. Natal/RN: EDUFRN, 2014.

DIAS, Reinaldo. Sociologia \& Administração. Campinas, SP: Editora Alínea, 2004.

DA SILVA, Maria Cristina Amaral e GASPARIN, João Luís. A segunda revolução industrial e suas influências sobre a educação brasileira. Disponível em: http://www.histedbr.fe.unicamp.br/acer histedbr/seminario/seminario7/TRABALHOS/ M/Marcia\%20CA\%20Silva\%20e\%20\%20Joao\%20L\%20Gasparin2.pdf. Acesso em 14 de agosto de 2019.

REINECKE, Gerhard. Qualidade de emprego e emprego atípico no Brasil. In. POSTHUMA, Ana Caroline (org.). Abertura e ajuste do mercado de trabalho no Brasil: políticas para conciliar os desafios de emprego e competitividade. Brasília: OIT e MTE, São Paulo: Ed. 34, 1999.

SCHWAB, Klaus. A quarta revolução industrial. São Paulo: Edipro, 2016.

TESSARINI JUNIOR, Geraldo e SALTORATO, Patrícia. Impactos da indústria 4.0 na organização do trabalho: uma revisão sistemática da literatura. Revista Produção Online. Florianópolis, SC, v. 18, n. 2, p. 743-769, 2018. Disponível em: file://C:/Users/CHICOD 2/AppData/Local/Temp/2967-10174-1-PB.pdf. Acesso em 15 de agosto de 2019.

CONFEDERAÇÃO NACIONAL DA INDÚSTRIA. Oportunidades para a indústria 4.0. Aspectos da demanda e oferta no Brasil. Brasília, DF: CNI, 2017. 


\section{Revista Labor}

Programa de Pós-graduação em Educação, Universidade Federal do Ceará Fortaleza-CE-Brasil

\section{Ana Patrícia Dias Sales \\ Fortaleza, Ceará e Brasil}

Doutorado em Sociologia pela Universidade Federal da Paraíba (2011), com estágio doutoral no Centro de Estudos Sociais (CES), em Coimbra. Atualmente é professora adjunta do curso de Ciências Sociais da Universidade Federal do Rio Grande do Norte e do Programa de Pós-Graduação em Estudos Urbanos e Regionais - PPEUR. É pesquisadora da temática do trabalho e suas metamorfoses com ênfase nos estudos sobre precarização, flexibilização, reestruturação produtiva, terceirização, trabalho e qualificação profissional e uberização

Email: anapatricia_dias@yahoo.com.br

Link do Lattes: http://lattes.cnpq.br/8695979411366952

\section{Francisco José Lima Sales}

Fortaleza, Ceará e Brasil

Doutor em Educação pela Universidade Federal do Rio Grande do Norte (2006). Professor da Universidade Federal do Ceará (UFC), lotado no Departamento de Estudos Especializados da Faculdade de Educação (FACED). É membro do Laboratório de Estudos do Trabalho e Qualificação Profissional da UFC (LABOR). Atua ainda no Programa de Pós-Graduação em Educação Brasileira, da mesma universidade, no eixo Economia Política, Sociabilidade e Educação, da Linha de Pesquisa Filosofia e Sociologia da Educação.

Email: chicodede@gmail.com

Link do Lattes: http://lattes.cnpq.br/7292939799937922

Recebimento: 01/06/2020

Aprovação: 08/06/2020

\section{Q.Code}

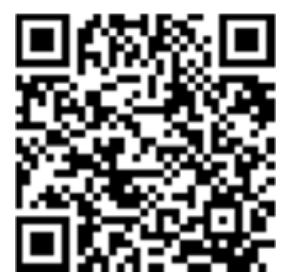

\section{Editores-Responsáveis}

Dr. Enéas de Araújo Arrais Neto, Universidade Federal do Ceará, UFC, Ceará, Brasil

Dr. Sebastien Pesce, Universidade de Orléans, França 